\title{
Two, Four, Six, Eight: Educating Twins, Triplets and More
}

\author{
David A. Hay' and Pat Preedy ${ }^{2}$ \\ 'Curtin University, Western Australia \\ ${ }^{2}$ Knowle $C$ of E Primary School, Solihull, England
}

\section{Introducing www.twinsandmultiples.org}

At the 2001 ISTS Congress in London, we launched the Multiples in School web site. The web site was funded as an international resource by the Australian Multiple Birth Association (AMBA), its United Kingdom (UK) equivalent, Twins and Multiple Births Association (Tamba) through the Cherry Rowland Foundation and by Curtin University. People are free to disseminate the web site information in any appropriate way (with due acknowledgement) but must not charge for the information. It is supported by the Council of Multiple Birth Organisations (COMBO), a working party of ISTS and assessing the impact of the web site is one of the COMBO objectives for the next Congress. This site provides information and downloadable resources for parents of multiple-birth children and for everyone who works with these families, whether they be teachers, school administrators or educational support staff.

There is surprisingly little reliable research on multiples in school. Along with AMBA, in 1989 David Hay conducted a national survey on twins in school and after workshops throughout the country developed the Twins in School booklet which was the precursor to this web site. Pat Preedy became interested in multiple birth children in 1992, when nine sets of twins started at her school. This event prompted her $\mathrm{PhD}$ which included surveys of 3000 schools, interviews with parents and analyses of the multiple data in the Performance Indicators In Primary Schools Tests to which she had earlier contributed. In summary, both in the
UK and in Australia we have used three complementary approaches:

- large-scale surveys of parents and teachers and (in the UK) headteachers

- analysis of data on multiples from national surveys of the school population

- work with individual families and children.

One impetus for developing the web site was the striking similarity between the results in the UK and Australia. However, it has proved to have very general appeal throughout the world. There have been some 60,000 hits already and requests to translate some sections of it into other languages

The content of the web site is very extensive and would run to some 250 pages if printed out. Developed by a professional web site design company, it makes extensive use of pulldown menus and hyperlinks to ensure people can get to the information they want as quickly as possible. The web site recognises that no two families are the same and the approach that worked with one set of multiples may not work with the next. Thus it uses the strategy of downloadable questionnaires which families and schools can complete to consider together all the issues that may be involved in such decisions as school readiness and classroom placement for a particular set of multiples.

There are plans to modify the web site at least once a year as time permits and as new issues arise. A "What's New?" box on the homepage leads people to new developments. One intention just now is to develop resource material that could be used in a class with trainee teachers to increase their awareness of multiple-birth issues.
The web site has four main sections, followed by a section with links and with forums. To stimulate use of the forums, each section ends with a question that reflects the theme of that section.

\section{Multiple Facts and Figures}

The policy in our education area is that all children start school in the year they turn 5 . Not only would my triplets be among the youngest in the class, they were born at 29 weeks. Neither the preschool nor the school seem to listen when I say that if they had been born when they should have been, they would not be five 'til, the next year. How do you decide what to do?

Some of this section is particularly for teachers, to increase their awareness of multiple birth issues such as the chances of preterm birth. There is discussion of zygosity and a questionnaire parents can use.

\section{Preschool}

Michael and John are MZ twins about to start school. They have poorly developed speech and language and have had few experiences of separation prior to starting school. They frequently combine to be disruptive. What would you do?

This section deals with some of the differences between multiples and singletons that often appear in the preschool years and are associated with the special relationship that can develop between multiples. A model is introduced to identify the pluses and minuses of such relationships.

Address for correspondence: David A. Hay, Professor of Psychology, Curtin University, GPO Box U1987, Perth WA 6845, Australia. Email:d.hay@curtin.edu.au 


\section{The School Years}

Sharon and Tom are 8. Tom has always been the smaller and spent longer in hospital after they were born. Sharon is doing well in class, at sport and has lots of friends. Tom is not doing well at school and is becoming very moody and irritable. He does not want to do 'anything'. Mum says she wishes there was just one thing Tom could do as well or better than Sharon. What can/should the parents and school do?

As well as the question of separation in school (including a checklist to help in decision-making), this section covers issues of school performance, of multiples in secondary school and provides schools with some ideas about how to develop an appropriate policy for multiples.

\section{Supporting Multiples with Special Needs}

John is 16 . His twin brother Alan has Cerebral Palsy and is at the same school. Alan can get around OK but looks conspicuously different. John is getting resentful. Apart from the jokes about his brother, John is sure Alan is the reason why he does not have a girlfriend, while most of his friends do. He is talking of dropping out of school and leaving home. What can be done now and what should have been done before?

Unfortunately there is a higher rate of physical and sensory difficulties among multiples. Some behavioural problems such as Attention Deficit Hyperactivity Disorder (ADHD) are also a little more common and a checklist for ADHD is included. Particular emphasis is put on how the multiple(s) without difficulties manage in this complex family situation.

\section{Multiple Links}

This section has two roles, providingweblinks to:

- research sites

- parent organisations throughout the world

- special interest groups such as loss of a multiple.
- There are forums for discussion about questions such as the ones raised above. There are three separate forums for:

- multiples themselves

- parents

- professionals.

While the web site was primarily designed as a source for families and teachers, it is useful for the many researchers in ISTS who are often asked about such topics by participating families. In addition, the listing of research web sites does allow families to identify which multiple birth research projects may be happening in their area and this could assist recruitment.

The web site has just been extended to include a downloadable flyer designed to publicise the web site and to encourage its use by families and schools. Researchers may find this flyer a useful resource for their participating families. It does include space to insert information about local research projects or resources. 